\title{
AN HISTOLOGIC STUDY OF THE EFFECTS OF EXPERIMENTAL BOTULINUS POISONING ON THE LIVERS OF GUINEA PIGS
}

\author{
By DONALD E. SHAY \\ (From the Department of Bacteriology, University of Maryland, Dental School, Baltimore)
}

(Received for publication March 8, 1946)

\section{INTRODUCTION}

Studies of the effect of Botulinus toxin upon tissue cells have been confined entirely to nervous tissue. Such studies have seemed quite pertinent when it is considered that the main clinical manifestation of Botulinus poisoning is a paralysis of striated muscle. Histologic studies have been made of the entire central and peripheral nervous system with the view of determining the causative factor of this paralysis.

To explain the action of Botulinus toxin in producing motor paralysis, 3 theories have been advanced.

One view has explained the paralysis as due to a thrombosis in the blood vessels of the brain. Such pathology has been reported by Wilber and Ophulus (1) and Dickson (2). However, lesions within the brain, effected by the thrombosis, are not evident. This explanation of Botulinus toxin action has received little support.

In some cases of Botulinus poisoning a degeneration of the nerve cells in the motor nuclei of the spinal cord has been observed ( 3 to 7 ). The occurrence of such lesions has led to the belief that the Botulinus toxin directly affects motor nerve cells, and consequently their function is impaired with resulting paralysis. Considerable evidence has been accumulated which fails to support the above theory. First, Cowdry and Nicholson (8) made a very detailed study of the cytology of sensory and motor nerve cells, nerve fibers, and the neuroglia, but were unable, in any of the tissue, to determine microscopic evidence of the action of the toxin. The criterion used for determination of the toxic action of Botulinus was the Nissl substance within the cytoplasm of the nerve cell body. This chromophile substance is extremely labile, and its structure, distribution, and amount are of diagnostic value in determining the condition of the nerve cell. The effect of the toxin is mediated outside of the central nervous system, namely at the peripheral nerve endings, or else the activity is entirely a physiological one, which leaves no cellular manifestations.

Secondly, Dickson and Shevky (5) have reported that, frequently, lesions occur in motor nuclei which are not accompanied by paralysis in the respective muscles innervated by the affected nuclei. Also, lesions may persist in the motor nuclei for at least 2 weeks after the animal has recovered from all clinical evidence of the intoxication.

It thus becomes fairly evident that the motor paralysis resulting from Botulinus toxin is not mediated through the central nervous system. This, then, leaves the only possibility, the action is mediated through peripheral nerves: or at their terminations. Since no lesions along the nerve can be demonstrated, it would appear likely that the nerve endings are affected. Such action has been studied physiologically, as follows:

Edmunds and Long (9) have pointed out that the paralysis effected by Botulinus toxin is very similar to the action of curare, which blocks the nerve impulse at the myoneural junction. Further, when an animal intoxicated by Botulinus toxin is injected with epinephrin or physostigmin, the involuntary muscles of the esophagus, stomach, and intestine act in a normal manner. Epinephrin and physostigmin act on the motor nerve endings as does curare. Such evidence indicates that certain symptoms of Botulinus toxin poisoning, such as constipation, difficulty in swallowing, etc., are not due to an action of the toxin on structures (namely, nerve terminals) located in the gastrointestinal wall. The exact action of the toxin resulting in constipation, etc., has not been accurately determined. The curare-like action of the toxin, together with an absence of microscopal derangement of nerve cells or fibers (8), strongly supports the contention that the activity of Botulinus toxin in some way affects the motor nerve endings. Such structures are exceedingly difficult to study histologically. The only satisfactory 
technique for their demonstration is either by impregnations with osmic acid or silver salts, or by methylene blue staining. All techniques are worthless for studying structural differentiations, for the entire organ is uniformly colored. Hence, it is very doubtful if any changes within the nerve endings, as caused by Botulinus toxin, can be demonstrated. The change, or action, is most probably a physiological one with little cytoplasmic change, as suggested by the action of many drugs upon the nervous system.

A review of the literature relative to the effects of Botulinus toxin upon tissues has shown a complete absence of experimentation on the effect of toxin on non-nervous tissue. In the early stages of this work it was noted that in toxin-injected animals, such organs as the liver, kidney, spleen, and intestinal tract showed marked abnormalities. The liver has been selected for this report because the tissue changes are more striking than any of those occurring in the above-mentioned organs.

\section{MATERIALS AND METHODS}

Normal, healthy guinea pigs were used for this experiment. Their average weight was from 280 to 325 grams. Both male and female animals were used.

Injections were made with $\mathrm{Cl}$. botulinum toxin, a thermolabile extracellular toxin-strain A. The toxin was obtained by raising the organisms in veal-infusion broth. The cultures were passed through a series of 3 daily transfers in the media. They were then grown for 14 days in approximately $900 \mathrm{ml}$. of the same media in a 1liter flask. To avoid an increase in acidity during sterilization, the broth was prepared without dextrose, and just before inoculation sterile 20 per cent dextrose solution was added to give a 2 per cent concentration. All cultures were incubated at $35^{\circ} \mathrm{C}$. Before filtration, 5 per cent phenol solution was added to the pooled toxin to give a 0.5 per cent concentration. After filtration, the toxin was stored in the ice-box until ready for use. Stock cultures were maintained in dextrose semi-solid beef-infusion agar, $\mathrm{pH}$ 7.0.

After securing the toxin, it was standardized by establishing the minimum lethal dose for guinea pigs.

The methods of standardizing and preparing the toxin were similar to that used for diphtheria toxin as stated by Wadsworth (10). The M.L.D. determined for the guinea pig was $.0003 \mathrm{ml}$. Table I indicates the sex, dilution used, time of injection and time of death of each guinea pig used in the determination. The guinea pigs were injected with $2 \mathrm{ml}$. of the toxin dilution.

After the animals were injected, they were held under very close observation, and notations of symptoms were made.
TABLE I

Results of injections of Bacillus Botulinus toxin into guinea pigs to establish the minimum lethal dose (M.L.D.)

\begin{tabular}{c|c|c|c|c}
\hline \hline No. & Sex & Dilution & $\begin{array}{c}\text { Time of } \\
\text { injection }\end{array}$ & Time of death \\
\cline { 2 - 3 } 1 & 9 & 0.00003 & $9: 15$ A.M. & $*$ \\
2 & 9 & 0.00005 & $9: 30$ A.M. & $*$ \\
3 & $\sigma^{7}$ & 0.0001 & $9: 45$ A.M. & +112 hours \\
4 & 9 & 0.0002 & $10: 00$ A.M. & +108 hours \\
5 & 9 & 0.0003 & $10: 15$ A.M. & -92 hours \\
6 & $\sigma^{7}$ & 0.0004 & $10: 30$ A.M. & -72 hours \\
7 & $\sigma^{7}$ & 0.0005 & $10: 45$ A.M. & -47 hours \\
\hline
\end{tabular}

* animals lived.

- death occurred before 96 hours.

+ death occurred between 96 hours and 5 days.

The first symptom to appear was a difficulty of the animal in swallowing; this was probably due at least in part to the paralysis of the pharyngeal muscles. Simultaneously with an increase in the difficulty of breathing, mydriasis was noted. This indicates a loss of accommodation for near vision, and imperfect function of the oculomotor nerve. Progressive muscular weakness was very marked, resulting in the inability of the animals to lift their limbs, to move about in their cages, or, in later stages, to lift their heads. The weakness in breathing was probably due to a paralysis of the diaphragm. Respiratory movements tend to be lost first from the lower regions of the thorax. In later stages, the movement of the upper ribs becomes gradually diminished until respiration stops. All the animals, regardless of sex, displayed identical symptoms.

All animals, regardless of dilution used, showed the same period of action of toxin prior to death. Thus, an animal injected with a high dilution of toxin would live longer than an animal injected with a low dilution. But prior to death, both animals would exhibit symptoms over the same period of time.

The animals at the point of death were immediately killed and dissected. The tissues removed include the vagus and recurrent nerves, liver, large and small intestines, kidney and spleen. After removal of the tissues from the animal, the pieces were placed in 2 separate fixatives; Bouin's and Zenker's. These 2 fixatives were used in order to observe the difference, if any, in the tissue due to fixation. After fixation the tissue was dehydrated and embedded in paraffin. All sections were cut at 8 micron. The sections were mounted and stained in either Heidenhain Azain or Harris's hematoxylin.

\section{OBSERVATIONS AND DISCUSSIONS}

\section{A. The histology of the normal guinea pig liver}

Blood circulation through the liver is of distinctive distribution. At the periphery of the lobules, embedded in considerable connective tissue, are the interlobular veins (Figure 1). In the 
PLATE I

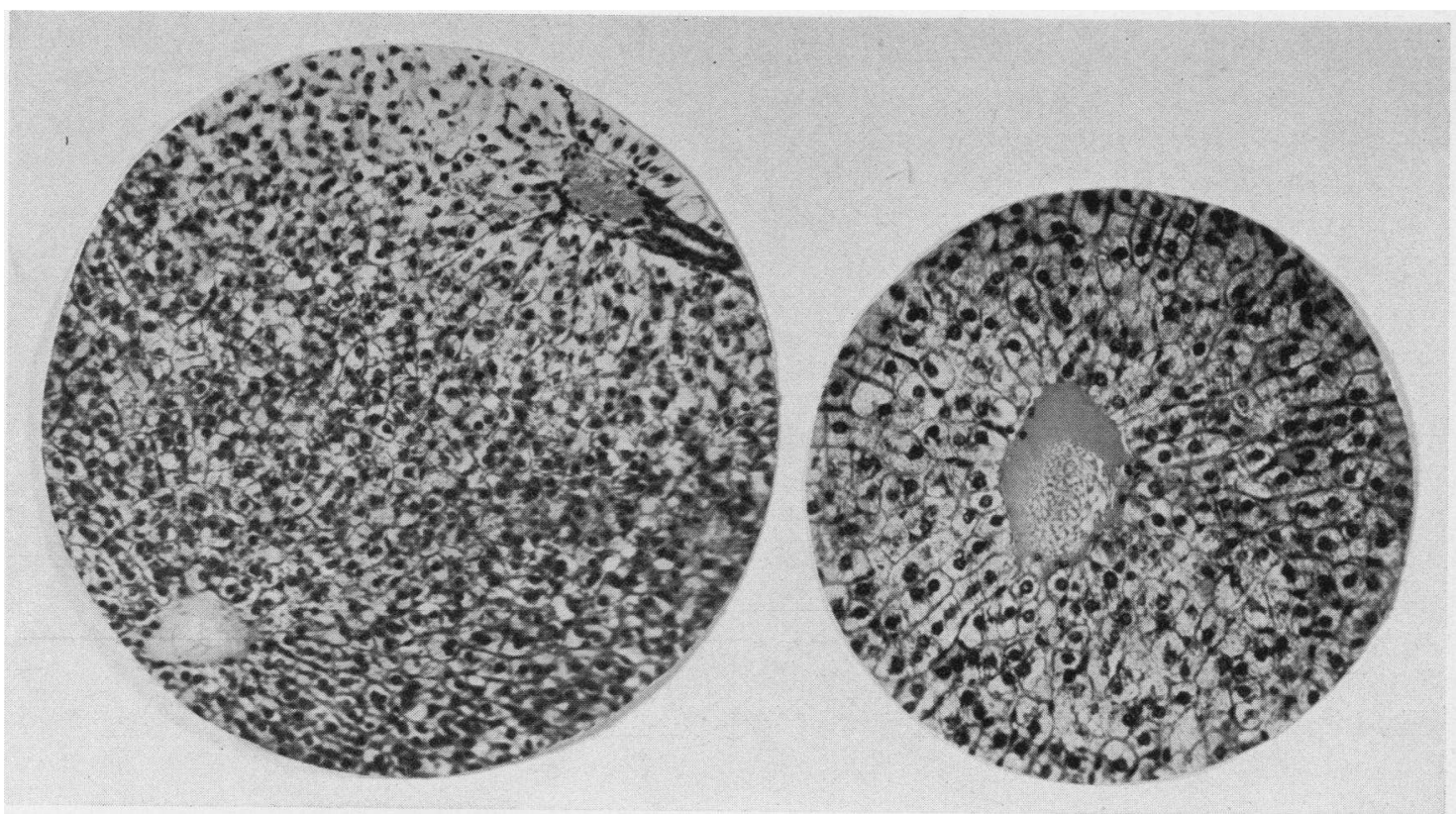

Fig. 1. A Section of Liver Tissue of a Non-injected GuINEA PIg.

This shows arrangement of the tissues in the lobule,

Fig. 2. Central Vein of Previous Figure Enlarged to Show Arrangement of Cell Cords. central vein, and interlobular vein.

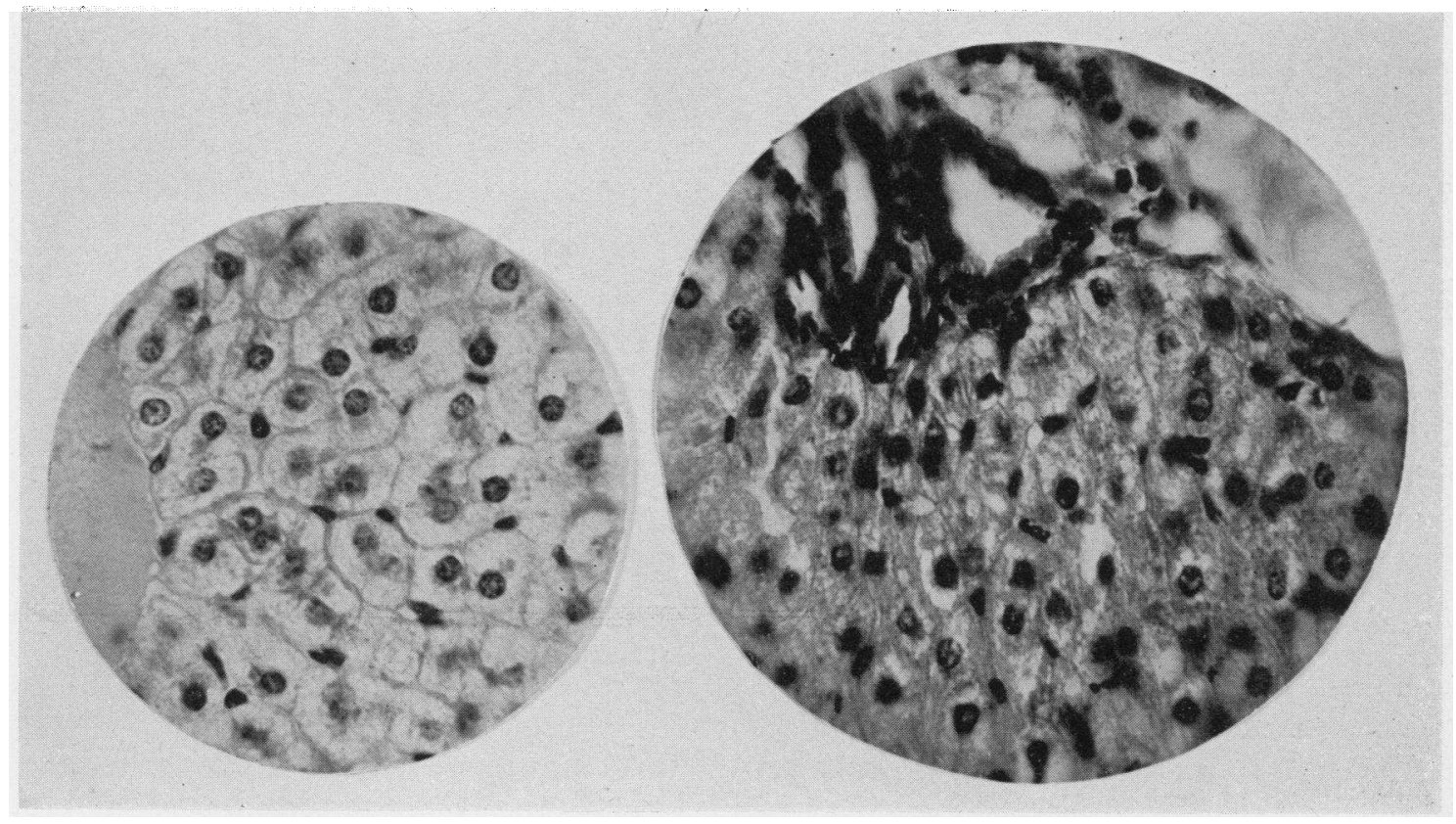

Fig. 3. Cells in the Region of the Central Vein.

This shows finely dispersed chromatin in the nuclei, homogeneous cytoplasm with reticular framework, and sinusoids with endothelium.
Fig. 4. A Section in the Region of the Portal Canal.

This shows interlobular bile ducts surrounded by cuboidal epithelium of an injected animal. 
center of the lobule occurs a single relatively large vein, termed the central vein, a branch of the hepatic vein (Figures 1 to 3,6 to 8 ). These veins may be distinguished from the interlobular veins by their size and slight amount of surrounding connective tissue.

The hepatic cells radiate in cords or traneculae, from the central vein to the periphery of the lobule. The periphery may be marked by a slight accumulation of connective tissue and the presence of the afore-mentioned interlobular veins. The arrangement of cells in cords, however, is not as evident in the periphery of the lobule as in the region of the central vein. Between these cords are blood spaces, the hepatic sinusoids, lined with endothelium. These sinusoids are minute channels, frequently distinguished only by the occasional endothelial cell, or blood cells, along their course (Figures 2, 3).

The hepatic cords are made up of cells which are polyhedral in shape, having 6 or more surfaces. The cells contain a single large spherical nucleus. Occasionally binucleation occurs.

The chromatin material in the nucleus is finely dispersed, with few chromatin knots, or masses. Usually each nucleus contains a single, or possibly 2 or 3, chromatin nucleoli (Figure 3). The cytoplasm of the hepatic cells appears homogeneous after the routine fixatives and stains. Occasionally small vacuoles (remnants of either fat or glycogen) are visible. The finely granular cytoplasm shows a very definite reticular framework (Figure 3).

One of the most important functions of the hepatic cell is to secrete bile, which aids in the hydrolysis of fat. This secretion is conducted by a delicate arrangement of fine bile capillaries, which may be demonstrated with suitable techniques. These capillaries parallel the sinusoids, and their walls are formed by the adjoining liver cells. The bile canaliculi, as they are called, receive short lateral branches which extend between the adjoining liver cells. The fine bile capillaries communicate with the interlobular bile ducts located at the periphery of the lobule and usually adjoining the interlobular veins (Figure 4). The lumena of these ducts are surrounded with cuboidal epithelium. The bile ducts fuse to form the common bile duct. This is joined by the cystic duct from the gall bladder to form the common bile duct. This unites with the pancreatic duct and passes into the duodenum at the ampulla of Vater.

\section{B. The histological effect of B. toxin upon the hepatic cells}

The histological appearance of the liver, after toxin injection, shows a very marked effect by the toxin, more so than any other organ studied.

When the body cavity was opened the liver was examined to determine the presence of external lesions. However, the only change noted was a darkening of the liver tissue, probably due to the diffusion of large amounts of blood.

In histological preparations it was noted that there were large areas in which complete necrosis had set in (Figure 5). These areas showed a general breakdown of hepatic cells. The spaces formed by this breakdown were filled with necrotic tissue, degenerate nuclei, connective tissue fibers, blood plasma and blood cells.

After a closer microscopic examination of individual lobules, it was noted that degeneration of cells began in the regions of the central veins (Figure 6). The cells in the region of the interlobular veins showed little effect of the toxin (Figure 7). The extent to which necrosis had progressed in the lobules was variable, some regions being of more advanced stages than others (Figures 4, 5, 7). In those affected to a lesser degree by the toxin, the only noticeable change was a very slight vacuolization of the cells and little or no effect on the surrounding blood vessels, etc. Other cells, effected to a greater extent by the toxin, exhibited conspicuous vacuolation of the cytoplasm, and the concentration of the nuclear material. This is clearly demonstrated in Figure 6.

Figures 6 and 8 show various stages of necrosis in the region of the central vein (Figure 8 to a greater extent than Figure 6). These may be compared to Figure 7, which exhibits a region around the vessels in the periphery of the same lobule from which Figure 8 was made. This, again, shows the greater amount of necrotic tissue around the central vein of the more advanced stages of degeneration. The bile ducts show little or no effects of the toxin.

The characteristic effects of the toxin is best illustrated in Figure 8. This shows a complete breakdown of the central vein, sinusoids and bile 


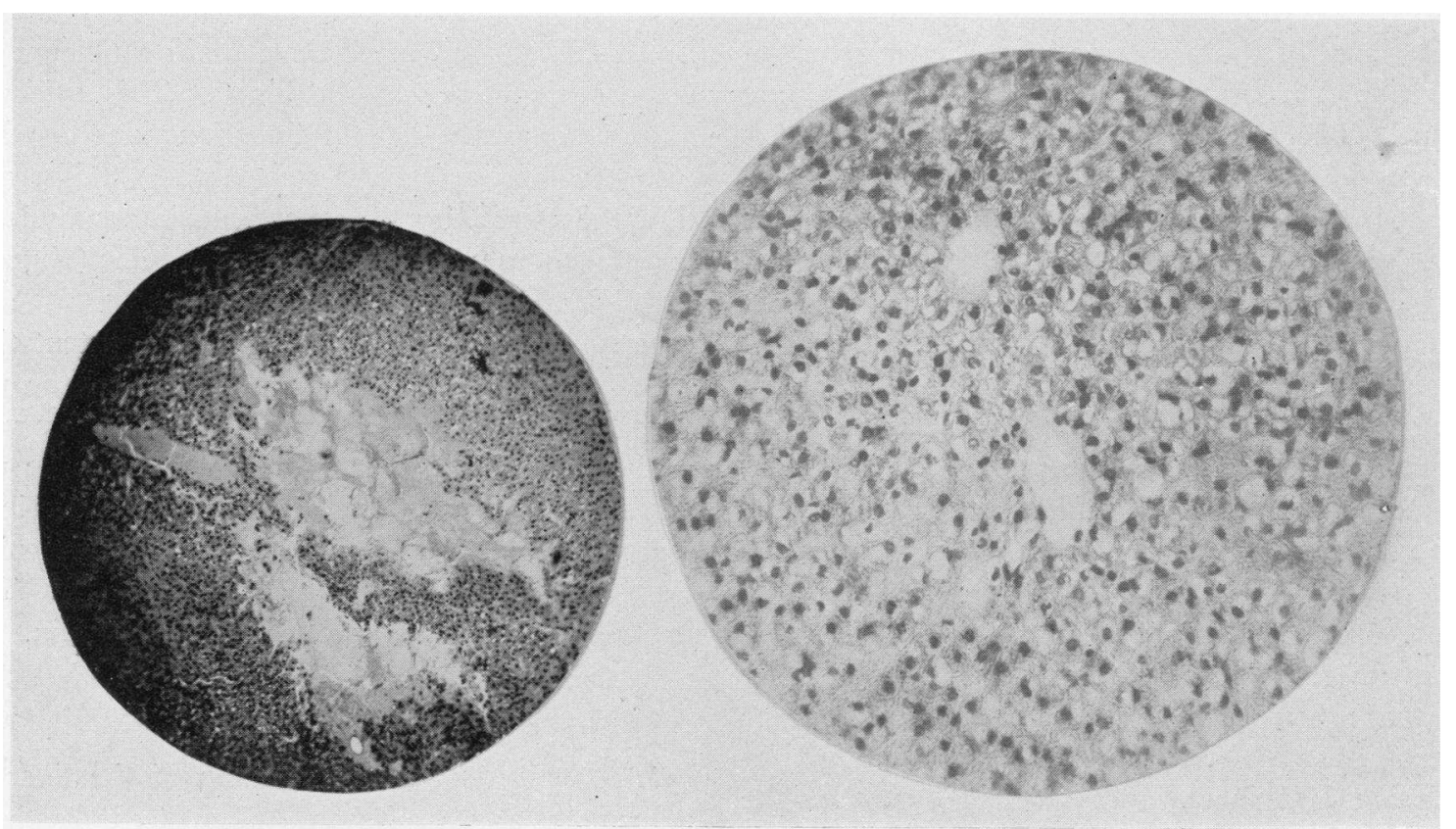

Fig. 5. A Breakdown of Hepatic Tissue as the ReSULT OF INJECTION OF Botulinus Toxin.

The resulting spaces are filled with necrotic tissue, degenerating nuclei, connective tissue and blood cells.
Fig. 6. Cellular Degeneration of the Region Surrounding the Central Vein as the Result of INJecting Botulinus Toxin.

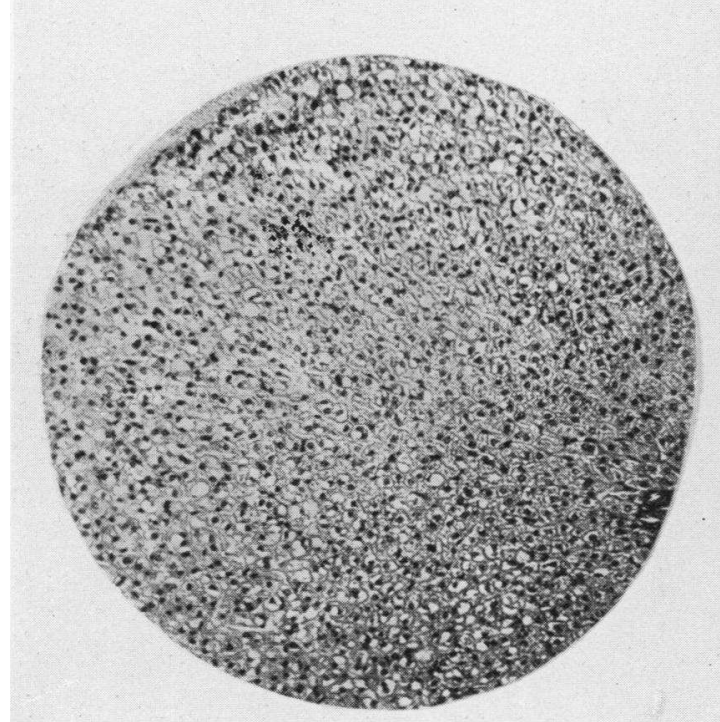

Fig. 7. Greatest Cellular Degeneration in the Entire Lobule May Be Seen in the Region of the Central Vein.

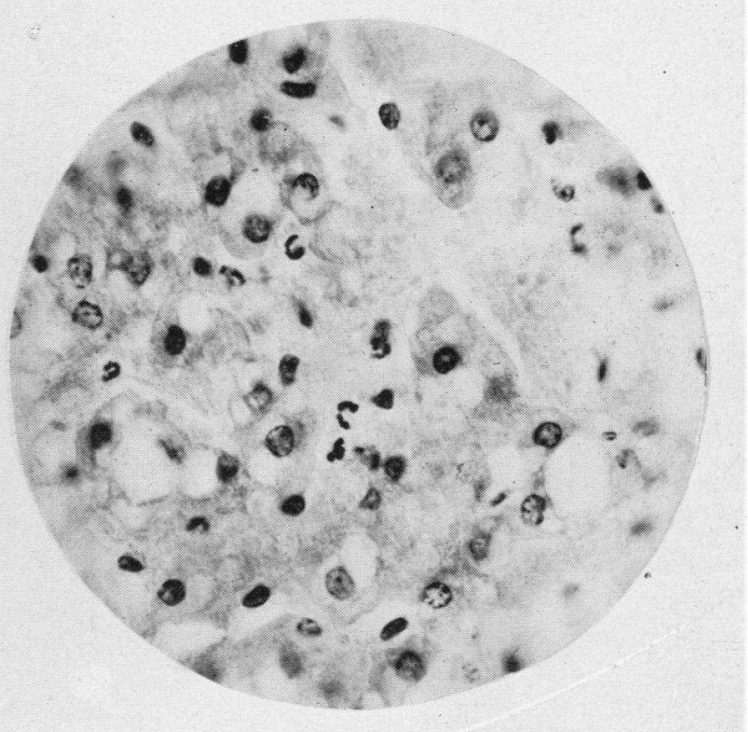

Fig. 8. Advanced Stages of Degeneration in the REgion of the CENTRAL VEIN.

This shows sinusoids, bile capillaries, and supporting connective tissue destruction resulting in infiltration of blood through the areas. Cytoplasmic vacuolization, accompanied by nuclear fragmentation and condensation of chromatin material (pyknosis), is in evidence. Polymorphonuclear leukocytes and erythrocytes are more stable, showing little, if any, effect of the toxin. 
capillaries, and complete destruction of the endothelial cells lining these vessels and spaces. A breakdown of these vessels results in a great infiltration of blood throughout this area of necrotic tissue. The supporting connective tissue in this region does not have its characteristic arrangement, but is distributed in the form of irregular bundles.

Areas which show variable effects of the toxic action offer a means of studying the progress of degeneration in the hepatic cell. A study of such regions clearly demonstrates that cytoplasmic vacuolization represents the method of degeneration of the cell. This cytoplasmic vacuolization is accompanied by marked changes in the nucleus, which result in condensation of chromatin material (pyknosis) and fragmentation of the nucleus (Figure 8). In areas slightly affected by the toxin the cells show an accumulation of minute vacuoles adjacent to the nucleus. Apparently by a fusion and increase of vacuolar material the vacuoles become progressively larger in size to the extent of completely surrounding the nucleus. A few strands of cytoplasm connect the nucleus with the peripheral layer of the cell. This peripheral layer of cytoplasm shows a marked condensation of material as compared to the normal. Its density is greatly increased, as indicated both by a greater affinity for stains and by its optical properties. This condensation may be due simply to the forcing of all cytoplasm to the periphery of the cell by the enlargement of the centrally located vacuoles. As yet, no determinations have been made as to the constituents of the vacuoles in the hepatic cells.

Lipoidal material in the liver cells appears in the form of vacuoles. However, fat vacuoles in cells exclusive of adipose tissue invariably show no confluence of vacuoles. Since, in the liver cells affected by Botulinus toxin, the final result is an individual large vacuole formed by the fusions of smaller ones, it is doubtful if the vacuolar material could be fat.

That the vacuolar material may be an accumulation of toxin is suggested by the work of Schneider and Fisk (11). These workers developed a method of testing for the presence of Botulinus toxin in the blood and tissues after death. Such procedure is valuable in diagnosing accurately suspected cases of Botulism. Schneider and Fisk
(11) were able to demonstrate the presence of toxin in the liver in all cases of death due to Botulism. At the same time, toxin could not always be identified in the blood. This evidence strongly suggests that the liver functions to withdraw the toxin from the circulating fluids, and thus the possibility that the toxin is accumulated within the vacuoles of the hepatic cells (Figures 6 and 8).

Some cells have degenerated to the extent that all that remains of the cell is a mass of the nuclear chromatin with no evidence of nuclear wall or cytoplasm. Leukocytes, which tend to be numerous in this region, appear to be more stable in regard to the toxin. Polymorphonuclear leukocytes are the predominant type (Figure 8 ). The red cells showed no visible effect of the toxin.

\section{SUM MARY}

1. An histological examination of the liver of guinea pigs at death from Botulinus toxin has been made.

2. The effect of the toxin is noticed particularly in regions adjacent to the central vein. Occasionally cells adjacent to the interlobular veins are affected.

3. The toxin acts first to produce a vacuolization of the cytoplasm within the hepatic cells.

4. Vacuolization progressively increases until only the nucleus remains, and an actual rupture or disintegration of the cell wall results.

5. Vacuolization is accompanied in the nucleus by pyknosis and fragmentation of nuclear material, nuclear characteristics of degeneration.

6. Conspicuous areas of complete necrosis of liver cells are present. These areas are marked by a great infiltration of blood plasma and cells. Such areas invariably are adjacent to the central veins.

7. It is suggested that the liver functions to remove the toxin from the circulating fluids, and the contents of the cytoplasmic vacuoles in the hepatic cells represent an accumulation of this toxin.

\section{ACKNOWLEDGEMENT}

The writer is indebted to Dr. Walter L. Hard, Department of Anatomy, Medical School of South Carolina, for initiating this study and for much valuable help during its progress. 


\section{BIBLIOGRAPHY}

1. Wilber, R. L., and Ophulus, W., Botulism. A report of food poisoning apparently due to eating of canned string beans, with pathological report of a fatal case. Arch. Int. Med., 1914, 14, 580.

2. Dickson, E. C., Botulism. A Clinical and Experimental Study, monograph of the Rockefeller Institute of Medical Research, No. 8, New York, 1918. Botulism, a further report of cases occurring in the Pacific coast states. Arch. Int. Med., 1918, 22, 483.

3. Marinesco, G., Pathologie generale de la cellule nerveuse; lesions secondaires et primitives. Presse Med., 1897, 5, 41.

4. Noack, W., Mitteilungen über Botulismus, Deutsch. Med. Wchnschr., 1917, 43, 1312; Beitrage zur Frage des Botulismus, Ztschr. klin. Med., 1919, 88, 304.

5. Dickson, E. C., and Shevky, R., Studies on the manner in which the toxin of clostridium botulinum acts upon the body. J. Exper. Med., 1922, 37, 711.
6. Kempner, W., and Pollack, B., Die Wirkung des Botulismus Toxins (Fleischgiftes) und Seines Specifischen Antitoxins auf die Nervenzellen. Deutsch. Med. Wchnschr., 1897, 23, 505.

7. Osaipoff, V. P., Influence de l'intoxication botulinique sur le systeme nerveux central. Ann. Inst. Pasteur, $1900,14,760$.

8. Cowdry, E. V., and Nicholson, F. M., An histological study of the central nervous system in experimental Botulinus poisoning. J. Exper. Med., 1924, $39,827$.

9. Edmunds, C. W., and Long, P., Contribution to pathologic physiology of botulism: paralysis due to the action of Botulinus toxin on the nerve endings of the motor nerves. J. A. M. A., 1923, 81, 542.

10. Wadsworth, A. B., Standard Methods of the Division of Laboratories and Research of the New York State Department of Health. 1939 (2nd Ed.), p. 378.

11. Schneider, H. J., and Fisk, R., Botulism: demonstration of toxin in blood and tissues. J. A. M. A., 1939, 113, 2299. 